\title{
Delayed TRAM in Breast Reconstruction
}

\author{
KARIMA ISMAIL, M.D.; MARIAM ISMAIL, M.D. and AHMED ISMAIL, M.D. \\ The Department of Plastic and Reconstructive Surgery, Faculty of Medicine, Cairo University
}

\begin{abstract}
Introduction: Breast reconstruction following modified radical mastectomy has evolved into either autogenous or implant depending reconstruction. In autogenous breast reconstruction TRAM (transverse rectus abdominal myocutaneous) flap was previously considered the best modality. However, an incidence of $30-40 \%$ complication rate was linked to this flap. Accordingly, many surgeons shifted to use flaps depending on microsurgery in breast reconstruction; among these flaps is DIEP flap which is most commonly used. The aim of this study is to prove that delay of TRAM flap is an efficient method to decrease complication rate of such flap to a minimum.
\end{abstract}

Material and Methods: This is a retrospective study since 2010 till 2016, it involved 24 cases suffering from breast cancer and managed by modified radical mastectomy. All cases did delay breast reconstruction by delayed TRAM flap. The age varied from 40 years old to 65 years old with an average of 52.5 years old. All cases were obese BMI $>30,13$ cases $(54.1 \%)$ were diabetic, 10 cases $(41.6 \%)$ had previous caesarean section, 2 cases $(8.3 \%)$ had vertical abdominal wall scar. All patients went through a first stage of delay; after 2 to 3 weeks separation and inset of the flap was done.

Results: Follow-up was done for a minimum of 1 month. All flaps survived completely with no major complication. Early complications varied from 3 cases $(12.5 \%)$ had seroma, 2 cases $(8.3 \%)$ had dehiscence at the lateral border from mastectomy flap, 2 cases $(8.3 \%$ ) had hardening, redness and hotness. Late complications, 2 cases $(8.3 \%)$ had abdominal wall weakness.

Conclusion: Tips in the delay and harvest of the flap were emphasized by lower number of complications in this group of high-risk patients. Delayed TRAM is a safe reliable procedure that ensures long term desired aesthetic outcome \& less complication rate than DIEP free flap and TRAM.

Key Words: TRAM - Breast-Reconstruction.

\section{INTRODUCTION}

Breast reconstruction following modified radical mastectomy has evolved into either autogenous or implant depending reconstruction. In autogenous breast reconstruction, the transverse rectus abdominis flap (TRAM) has become the mainstay of breast reconstruction surgery since its introduction in 1982 and subsequent popularization by Har- trampf et al., [1]. Common goals for any breast reconstructive procedure are (1) Safe and well perfused volume of tissue transferred and (2) Minimization of donor site morbidity. Though differences of opinion continue to exist, TRAM has proven to be the safest and most reliable flap [2]. TRAM whole muscle technique flap is fast, reliable, requires no microsurgery and eliminates patient anxiety about total flap loss. Mid abdominal TRAM flap includes this perforator rich area and is constructed to take advantage of the more secure anterior supply and venous outflow. The anatomic basis for the midabdominal TRAM flap is corroborated by elegant in vivo studies performed by Harris et al. This study also showed that lower abdominal TRAM flaps depend on retrograde flow from the superior to the deep inferior epigastric artery to supply the skin island, again proving that the blood supply to the midabdominal TRAM flap is more secure and reliable [3]. The rate of hernia formation in a large series of midabdominal TRAM flaps was 2 percent, reflecting the advantage of limiting rectus muscle harvest to above the arcuate line. Although synthetic mesh can be selected for special instances of thin attenuated abdominal wall tissues, this low rate of hernia formation was achieved without the use of any foreign material [4]. Authors modified their design, preferring a similar flap using a lower abdominal transverse skin island. The aesthetic advantages of this design include a low suprapubic scar and concomitant abdominoplasty. However, harvest of the rectus muscle and fascia below the arcuate line increases the risk of hernia formation [5]. In autogenous breast reconstruction TRAM (transverse rectus abdominis myocutaneous) flap was previously considered the best modality as it is the safest and most reliable. However, an incidence of $30-40 \%$ of complications was linked to this flap. This complication rate varied between: Partial loss / sloughing,total loss of the flap, wound separation I dehiscence, fat necrosis, small flap, epigastric 
bulge and donor site morbidity: Abdominal weakness and frank herniation [1,5]. Therefore, many surgeons shifted to use flaps depending on microsurgery in breast reconstruction; of these flaps DIEP flap is most commonly used. Boyd et al., showed that the dominant arterial inflow to the rectus abdominis muscle is the deep inferior epigastric artery (DIEA) [6]. With this blood supply, the rectus muscle can carry a larger skin and subcutaneous paddle than can the rectus muscle when based on the superior epigastric vessels. Thus, there is less risk of ischemia to the peripheral zones of the flap. In 1989, Grotting et al., reported a comparison of the conventional pedicled TRAM flap with free TRAM flap [7]. There were no partial or total flap losses in the microvascular group, and one flap showed $25 \%$ loss in pedicled group. They concluded that, despite the added complexity of the microvascular reconstruction, the free TRAM was safe. This finding has been reinforced by later studies showing flap failures of only $1-2 \%$.

Several elements of the free TRAM justify its use. First, the vascular reliability of the deep inferior epigastric vessels allows more tissue to be carried on the flap and allows for more aggressive insetting and shaping of the new breast mound. This is particularly true in the case of smokers. Second, the epigastric bulge created by the folded rectus muscle pedicel of the conventional TRAM flap is eliminated when performed as a free flap, with no violation of the inframammary fold. In addition, donor site morbidity (abdominal wall hernia or eventration) decreases as less rectus muscle and fascia are harvested in the free flap, resulting in fewer abdominal wall closures under tension. Feller subjectively studied rectus muscle function after both procedures and has concluded that, with more rectus muscle remaining after the free flap harvest, there is less functional muscle weakness [8]. Contraindications to free TRAM flap, patients whom deep inferior epigastric vessels are previously divided, this includes patients who have undergone previous gynecological procedures via pfannenstiel incisions. Also, patients with significant comorbid conditions, such as unstable angina, complicated chronic obstructive pulmonary disease, liver or renal disease, irradiation, pheochromocytoma, or conditions resulting in refractory vasospasm, are poor candidates for free flap reconstruction because of the potential for blood pressure and perfusion derangements, severe volume depletion, or marked vasospasm.

All of the previous mentioned causes maybe relative or absolute contraindication for pedicled and free TRAM flap. Delay of the TRAM will allow us to expand the indications to include high risk patients and lessen complication rate to $10 \%$.

Methods of delay of pedicled TRAM flap:

- Cut skin only and undermining of zone 3 and 4.

- Cut skin only and undermining of zone 2, 3 and 4.

- Cut skin, undermining of zone 2, 3 and 4 and ligation of inferior epigastric artery of the side of the flap.

N.B: Bilateral ligation of inferior epigastric artery is not needed.

The aim of this study is to prove that delay of pedicled TRAM flap is an efficient method to decrease complication rate of such flap to a minimum.

\section{PATIENTS AND METHODS}

This is a retrospective study since 2010 till 2016 , it involved 24 cases suffering from breast cancer and managed by modified radical mastectomy. The age varied from 40 years old to 65 years old with an average of 52.5 years old. All cases were obese BMI $>30,13$ cases $(54.1 \%)$ were diabetic, 10 cases $(41.6 \%)$ had previous C.S, 2 cases $(8.3 \%)$ had vertical abdominal wall scar.

All patients went through first stage of delay:

- Draw skin island with careful inclusion of $4 \mathrm{~cm}$ skin above umbilicus.

- Open the skin island all over except 2 lateral pedicles.

- Undermining of zone $3 \& 4$.

- Open Rectus sheath between arcuate line and symphysis pubis to: Identify and ligate the deep inferior epigastric artery.

- Delineate lateral border of rectus sheath by proline 3/0.

- Cut superior border of the flap in a slanting manner to include some supra umbilical perforators.

- Drain.

- Close the incision by non-absorbable proline.

- Not less than 14 days.

Pre-operative markings:

- Midline

- 2 lateral lines of rectus abdominis on the abdomen.

- Meridian of the breast.

- Infra mammary fold.

- 2ND rib (upper breast fullness). 
- The ribs are numbered and marked.

- $4 \mathrm{~cm}$ above umbilicus.

After 2-3 weeks' patients operated upon:

- Seroma was always present and evacuated first.

- Dissect upper flap till Xyphoid.

- Leave a breadth of $3 \mathrm{~cm}$ rectus sheath.

- Elevation of the flap with meticulous preservation of paraumbilical perforators especially while delivering the umbilicus.

- Opening tunnel under the contralateral breast.

- Passage of flap in S-shape manner.

- Great attention is given in forming upper pole fullness and inframammary fold.

- Closure of breast and abdomen simultaneously.

- Proline mesh was always used in the anterior abdominal wall.

Optimizing the new breasts bymaking it same size as the other side with same upper pole fullness, same mound, same level of Inframammary foldand always discard any query area intra operative.

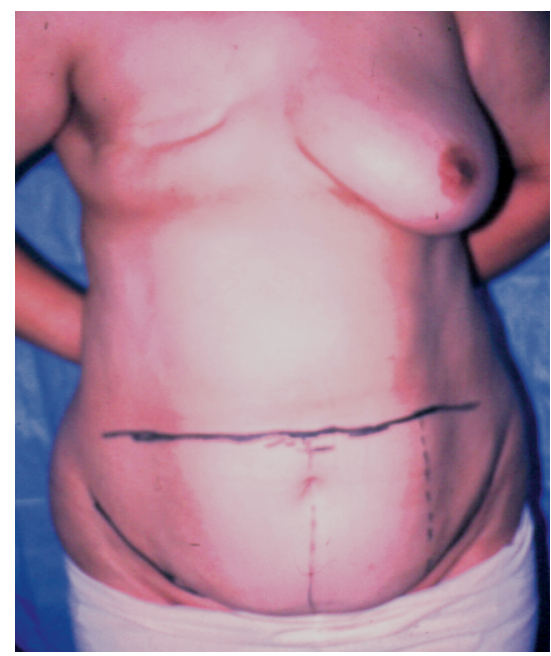

Fig. (1A): Pre-operative before delay.

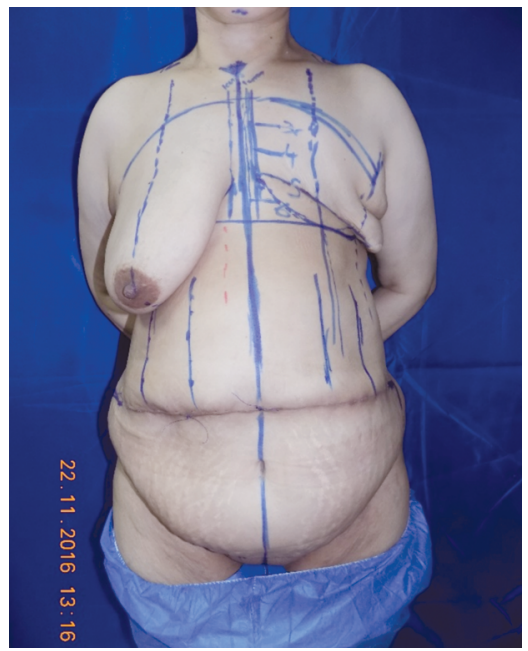

Fig. (2A): Second stage after delay.
Optimizing abdominal wall closure was obtained by using mesh, below arcuate line internal oblique muscle must be identified and closed, layered repair, drains are used and abdominal binder for 3 weeks.

We optimized flap survival by using delay technique, our incision was at least $4 \mathrm{~cm}$ above umbilicus, contralateral TRAM of reconstructed breast is used, the tunnel was as big as fist of the hand and any doubtful area better removed intra operative than later, excise till you reach bright red blood.

\section{RESULTS}

Follow-up was done for a minimum of 1 month. All flaps survived completely with no major complication. Early complications varied from 3 cases $(12.5 \%)$ had seroma, 2 cases $(8.3 \%)$ had dehiscence at the lateral border from mastectomy flap, 2 cases $(8.3 \%)$ had hardening, redness and hotness. Late complications, 2 cases $(8.3 \%)$ had abdominal wall weakness.

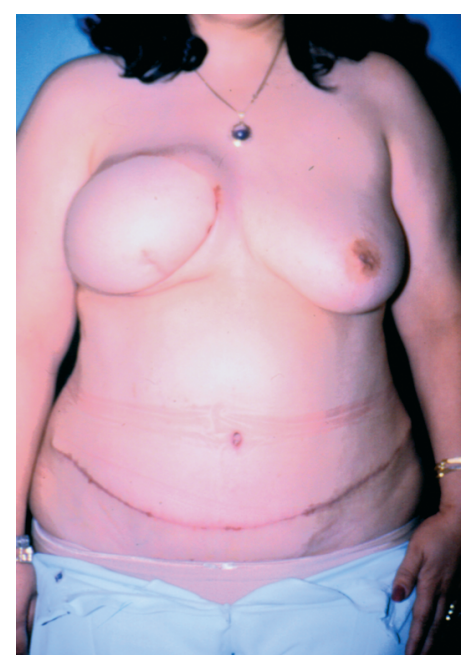

Fig. (1B): Post-operative.

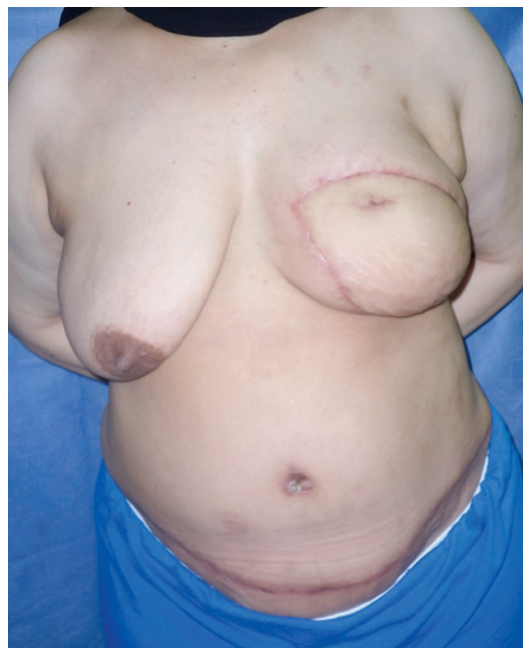

Fig. (2B): Post-operative. 


\begin{tabular}{|c|c|c|c|}
\hline & DIEP & TRAM & D-TRAM \\
\hline $\begin{array}{l}\text { Amount of tissue } \\
\text { harvested: }\end{array}$ & ++ & + & +++ \\
\hline Complications: & $\begin{array}{l}\text { 1- Complete loss of flap } \\
\text { 2- Wound dehiscence } \\
\text { 3- Fat necrosis }\end{array}$ & $\begin{array}{l}\text { 1- Partial loss } \\
\text { 2- Wound dehiscence } \\
\text { 3- Fat necrosis }\end{array}$ & $\begin{array}{l}\text { 1- No loss of flap } \\
\text { 2- No wound dehiscence } \\
\text { 3- Fat necrosis }\end{array}$ \\
\hline Abdominal Wall: & Minimal or not affected & $\begin{array}{l}\text { Weakness \& } \\
\text { maybe herniation }\end{array}$ & $\begin{array}{l}\text { No herniation, maybe } \\
\text { weakness, favorable } \\
\text { exaggerated waist line though }\end{array}$ \\
\hline $\begin{array}{l}\text { Microvascular } \\
\text { experience: }\end{array}$ & Needed & Not needed & Not needed \\
\hline Duration: & $6-12$ hours & 6 hours & $\begin{array}{l}2 \text { stage; } \\
1^{\text {st: }} 3 \text { hours } \\
2^{\text {nd: }} 6 \text { hours }\end{array}$ \\
\hline Hospital cost: & +++ & + & ++ \\
\hline
\end{tabular}

Fig. (3): Timetable comparing between free TRAM, Pedicled TRAM and Delayed TRAM.

\section{DISCUSSION}

Breast reconstruction following modified radical mastectomy has evolved into either autogenous or implant depending reconstruction. In autogenous breast reconstruction TRAM (transverse rectus abdominal myo-cutaneous) flap was previously considered the best modality. However, an incidence of 30-40\% complication rate was linked to this flap. Accordingly, many surgeons shifted to use flaps depending on microsurgery in breast reconstruction; among these flaps is DIEP flap which is most commonly used. However, in this study we proved that delay of the TRAM will decrease complication rate dramatically especially in high risked patients as documented by our results.

The following timetable is for comparison between free TRAM, Pedicled TRAM and Delayed TRAM:

In the current cost-cutting climate of health care, considerations of expense must be part of the selection process for any major procedure. Kroll et al., discovered a $4.1 \%$ increase in the resource cost of a free TRAM flap versus a conventional TRAM flap breast reconstruction [9].

\section{Conclusion:}

Tips in the delay and in the harvest of the flap were emphasized by lower number of complications in this group of high-risk patients. Delayed TRAM is a safe reliable procedure that ensures long term desired aesthetic outcome $\&$ less complication rate than DIEP free flap and TRAM. Cases that can be done efficiently by pedicle flap should not be done by micro surgery.

\section{REFERENCES}

1- Hartrampf C.R., Scheflan M. and Black P.W.: Breast reconstruction with a transverse abdominal island flap. Plast. Reconstr Surg., 69: 216-224, 1982.

2- Hartrampf C.R., ed.: Hartrampf"s Breast Reconstruction With Living Tissue. Norfolk, Va: Hampton Press, 1991.

3- Harris N.R. I.I., Webb M.S. and May J.W. J.r.: Intraoperative physiologic blood flow studies in the TRAM flap. Plast. Recontr Surg., 90: 553-558, 1992.

4- Slavin S.A. and Goldwyn R.M.: The midabdominal rectus abdominis myocutaneousflap: Review of 236 flaps. Plast. Reconstr Surg., 81: 189-197, 1988.

5- Nahai F.: Discussion of "Comparison of strategies for preventing abdominal wall weakness after TRAM flap breast reconstruction" (by Kroll S, Marchi M). Plast. Reconstr Surg., 89: 1052-1053, 1992.

6- Boyd I., Taylor G. and Corlett R.: The vascular territories of the superior epigastric and deep inferior epigastric systems. Plast. Reconstr Surg., 73: 1, 1984.

7- Grotting J.C., Urist M.M., Maddox W.A., et al.: Conventional TRAM flap versus free microsurgical TRAM flap for immediate breast reconstruction. Plast. Reconstr Surg., 83: 828, 1989.

8- Feller A.M.: Free TRAM. Results and abdominal wall function. Clin. Plast. Surg., 21: 223, 1994.

9- Kroll S.S., Evans G.R.D., Reece G.P., et al.: Comparison of resource costs of free and conventional TRAM flap breast reconstruction. Plast. Reconstr Surg., 98: 74-77, 1996. 